\title{
DESEMPENHO DE LINHAGENS DE LEVEDURAS ISOLADAS DA ALGAROBA NO CALDO DE CANA DE AÇÚCAR.
}

\author{
M. F. ALVES ${ }^{1}$ M. B.MUNIZ ${ }^{2}$ W. V. de SANTANA ${ }^{3}$
}

${ }^{1}$ Universidade Federal da Paraíba, Departamento de Engenharia Química

2 Universidade Federal de Campina Grande, Departamento de Engenharia de Engenharia Química

${ }^{3}$ Engenho São Paulo - Cruz do Espírito Santo - Paraíba

E-mail: manfalves@yahoo.com

RESUMO A vagem da algarobeira é uma matéria prima que vem sendo utilizada nas últimas pesquisas voltadas para a obtenção de bioprodutos, por se tratar de uma fonte natural de açúcares, proteínas e sais minerais. No presente trabalho, foram selecionadas e isoladas cinco linhagens a partir do caldo extraído da Algaroba, as quais foram testadas em caldo de cana de açúcar. Essas linhagens apresentaram ótimo desempenho na produção de fermento, aguardente e álcool utilizando o próprio caldo de Algaroba. Com base nesses resultados, as linhagens testadas em caldo de cana com o objetivo de avaliar o desempenho das mesmas no processo de fermentação tradicional e ao mesmo tempo, compará-las com o rendimento do fermento comercial. Os resultados obtidos mostraram que as linhagens de leveduras isoladas do caldo de Algaroba tiveram um bom desempenho quando submetidas ao caldo de cana de açúcar como meio de fermentação.

\section{INTRODUÇÃO}

Algaroba é o nome dado ao fruto da algarobeira. Trata-se de uma planta largamente difundida e cultivada na região do semi-árido do nordeste brasileiro. Esta planta foi introduzida no Nordeste durante a década de 1940, onde apesar de algumas controvérsias, se adaptou muito bem a essa região que, tem servido ao longo desses anos como ração animal. Todavia, essa cultura tem se adaptado em áreas inóspitas onde outras plantas jamais se adaptariam, sendo bem caracterizadas pelas suas raízes alongadas, capazes de captar águas subterrâneas a uma profundidade média de 30 metros, conforme reportado por AGIDE (1987). Outros cultivares, não muito comuns, chegam a atingir até 60 metros de profundidade. Cientificamente, pertence à família Leguminosae, subfamília Mimosoideae sendo eminentemente xerófila, onde atualmente 
são conhecidas cerca de 44 espécies. A espécie predominante no Brasil é a Prosopis juliflora, originária do deserto do Piura no Peru. Todavia, outras espécies, ao longo das últimas décadas, foram selecionadas para diversos fins, por meio de estudos vinculados a empresas especializadas como a Empresa Brasileira de Pesquisa Agropecuária EMBRAPA. Dentre estas, destacam-se principalmente, o Prosopis tamarugo, $P$. nigra, $P$. alba e $P$. chilensis, sendo as duas últimas, destinadas especificamente à produção de aguardente e álcool por via fermentativa, conforme ARRUDA (1994).

Além das características peculiares, a sua vagem é extremamente rica em proteína e componentes energéticos cujo teor de açúcares, chega a 40\%, em média, o que lhe confere o caráter bioenergético. Possuem proteína bruta com teores acima de 12\%, sendo constituída de proteínas digestivas em quase toda sua totalidade, (BARBOSA, FARIA; VILELA, (2007), além de sais minerais. Quanto às dimensões das vagens, não há uma uniformidade em termos de comprimento e largura, em geral, o seu tamanho médio é de $25 \mathrm{~cm}$ de comprimento e $1 \mathrm{~cm}$ de largura. $\mathrm{O}$ que tem se constatado nas últimas pesquisas é que as fontes nutricionais desse fruto somados aos teores de açúcar tem servido de meio de crescimento, por via fermentativa, (MUNIZ , 2009) para a obtenção de uma diversidade de bioprodutos que poderão ter interesse econômico. Segundo OLIVEIRA, (2005), o caldo extraído da algaroba naturalmente provido de excelente fonte nutricional também torna-se, à semelhança de outros, um meio susceptível a ocorrência de microrganismos. Com o objetivo de atender o desenvolvimento de outras alternativas biotecnológicas, tem se buscado a seleção e o isolamento de microrganismos que possam ter aplicabilidade e destinação específica em processos de fermentação tradicionais.

\section{MATERIAL E MÉTODOS}

Este trabalho foi desenvolvido no Laboratório de Engenharia Bioquímica da Universidade Federal de Alagoas - UFAL. Inicialmente, as vagens foram trituradas e submetidas a um processo de infusão a $50^{\circ} \mathrm{C}$ para facilitar a extração dos açúcares e em seguida prensadas. $\mathrm{O}$ caldo resultante da extração, foi utilizado para preparação das diluições em série como recomendado para seleção de leveduras de acordo com os procedimentos básicos da microbiologia. Após 7 dias pode-se avaliar o nível de tolerância às concentrações de açúcar adicionais. Do tubo de menor concentração, as células remanescentes foram transferidas para placas de Petri onde ocorreu naturalmente, a formação de colônias. Uma das colônias formada foi transferida para tubos de ensaio e incubadas por um período de 24 horas. As culturas puras isoladas, foram conservadas em tubos de ensaio a uma temperatura de $-5^{\circ} \mathrm{C}$ e estocadas para 
atender outros testes envolvendo a fermentação alcoólica=. Após a análise de biotipagem, por eletroforese, foram dadas as denominações especiais às linhagens isoladas do caldo de algaroba como sendo: ALG-01,_ALG-02, ALG-03, ALG-04 e ALG05. As leveduras selvagens foram microbiologicamente caracterizadas pelas suas peculiaridades como por exemplo, a forma de reprodução e o aspecto morfológico como por exemplo, a presença de células-filhas. A tipagem genética foi determinada a partir de uma levedura pura, da espécie Saccharomyces cerevisiae usada como padrão para a efetiva identificação por eletroforese, segundo SCAVUZZI, (2007). As linhagens isoladas algaroba foram usadas inicialmente na produção de fermento biológico, aguardente e bio-etanol utilizando o próprio caldo extraído da vagem como meio de fermentação. Os resultados decorrentes desses processos fizeram com que o potencial dessas linhagens de leveduras fosse aproveitado utilizando outros meios naturais, a exemplo do caldo de cana de açúcar.

\section{RESULTADOS E DISCUSSÕES}

Das cinco linhagens selecionadas do caldo de algaroba, duas tiveram destaque em relação à produção de biomassa. Pelas características observadas, pôde-se comprovar que as novas linhagens pesquisadas, taxonomicamente, apresentaram morfologia própria das leveduras. Dos cinco isolados analisados, duas linhagens a ALG-03 e ALG04 apresentaram um bom desempenho na produção de fermento quando o meio de cultivo foi o próprio caldo extraído da algaroba. A análise feita através amplificação de DNA, mostrou a tipagem genética das linhagens ALG-3 e ALG-4 provenientes do caldo de algaroba., como sendo do gênero Saccharomyces e não-Saccharomyces respectivamente. A tabela 1 mostra a tipagem genética de dez isolados de leveduras selecionadas a partir do caldo de Algaroba, conforme FERREIRA; GATTAPAGLIA (1996). Diante dos resultados apresentados que foram altamente positivos, principalmente fazendo uso do caldo de algaroba, fez com que as potencialidades dessas linhagens de leveduras tornassem possível um estudo comparativo utilizando o caldo de cana como meio de fermentação. Os experimentos usando caldo de cana puderam mostrar claramente um ótimo desempenho das leveduras selecionadas e isoladas do caldo de algaroba, até mesmo quando comparadas com o fermento comercial (Fermento Fleischmann).

Tabela 1 - Amplificação de DNA - iniciador $(G T G)_{5}$ 


\begin{tabular}{c|c|l}
\hline Isolado & Morfologia da colônia & \multicolumn{1}{|c}{ Tipagem Genética } \\
\hline ALG3 01 & Rugosa e pequena & Saccharomyces cerevisiae P1 \\
\hline ALG3 02 & Rugosa e pequena & Saccharomyces cerevisiae P1 \\
\hline ALG3 03 & Rugosa e pequena & Saccharomyces cerevisiae P1 \\
\hline ALG3 04 & Rugosa e pequena & Saccharomyces cerevisiae P1 \\
\hline ALG3 05 & Rugosa e pequena & Saccharomyces cerevisiae P1 \\
\hline ALG4 06 & Lisa e pequena & Não- Saccharomyces cerevisiae \\
\hline ALG4 07 & Lisa e pequena & Não- Saccharomyces cerevisiae \\
\hline ALG4 08 & Lisa e pequena & Não- Saccharomyces cerevisiae \\
\hline ALG4 09 & Lisa e pequena & Não- Saccharomyces cerevisiae \\
\hline ALG4 10 & Lisa e pequena & Não- Saccharomyces cerevisiae \\
\hline
\end{tabular}

A linhagem ALG-4 embora não sendo do gênero Saccharomyces, possui atributos de outras esspécies de leveduras que, também conduzem naturalmente à fermentação. As nãoSaccharomyces foram identificadas posteriormente como sendo do gênero Zygosaccharomyces. Este gênero é encontrado comumente nas fermentações com grau alcoólico abaixo de $7{ }^{\circ} \mathrm{GL}$ e, quando se tem uma acidez total acima do normal. Essas características são percebidas nos processos que usam caldo de cana irrigada com vinhaça e atacada pela cigarrinha, (NETO, 2005). A figura 1 (a e b) mostra o desempenho e a tipagem genética das leveduras.
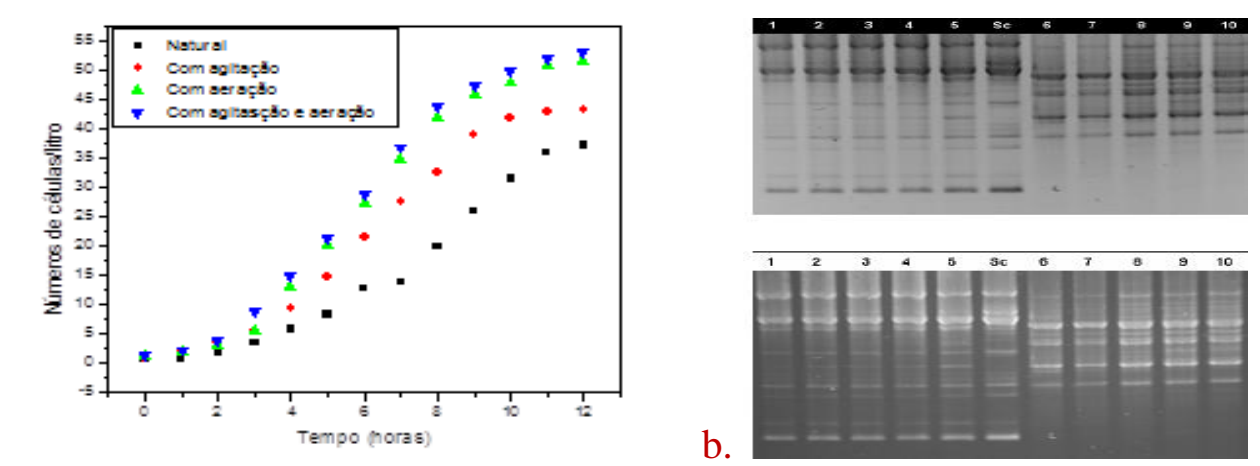

Figura 1 - Desempenho das linhagens isoladas do caldo(a) Tipagem genética das leveduras selvagens do caldo de algaroba(b).

As leveduras selecionadas e isoladas a partir do caldo de algaroba, foram então testadas em caldo de cana de açúcar procedente do Engenho São Paulo, com o propósito de avaliar o 
desempenho dessas novas linhagens na fermentação alcoólica, usando as faixas ótimas para o crescimento de leveduras recomendadas para esse tipo de processo.

Na Tabela 2 encontram-se os dados sobre a fermentação alcoólica com diferentes linhagens de leveduras selecionadas e isoladas de vagens da algarobeira e crescidas em caldo de cana de açúcar.

Tabela 2. Comportamento de diferentes linhagens de leveduras isoladas de vagens da algarobeira no caldo de cana de açúcar.

\begin{tabular}{|c|c|c|c|c|c|c|c|}
\hline \multirow{2}{*}{\multicolumn{2}{|c|}{ MONITORAMENTO DO CULTIVO }} & \multicolumn{6}{|c|}{ LINHAGENS } \\
\hline & & \multirow{2}{*}{$\begin{array}{r}\text { ALG-1 } \\
18,5\end{array}$} & \multirow{2}{*}{\begin{tabular}{|r|} 
ALG-2 \\
18,2 \\
\end{tabular}} & \multirow{2}{*}{$\begin{array}{r}\text { ALG-3 } \\
18,7\end{array}$} & \multirow{2}{*}{\begin{tabular}{|r|} 
ALG-4 \\
17,8
\end{tabular}} & \multirow{2}{*}{$\begin{array}{c}\text { ALG-5 } \\
17,8\end{array}$} & \multirow{2}{*}{$\begin{array}{r}\begin{array}{c}\text { Fermento } \\
\text { Fleischmann }\end{array} \\
18,2\end{array}$} \\
\hline \multirow{3}{*}{ MOSTO } & $A R T$ & & & & & & \\
\hline & \begin{tabular}{|l} 
CONC. \\
CELULAR
\end{tabular} & 2,3 & 2,3 & 2,3 & 2,3 & 2,3 & 2,3 \\
\hline & $p H$ & 5,2 & 5,3 & 5,2 & 5,3 & 5,3 & 5,3 \\
\hline \multirow{5}{*}{$\begin{array}{l}\text { MOSTO } \\
\text { FERMENTADO } \\
\text { POR } 48 \text { HORAS }\end{array}$} & $A R T$ & 2,4 & 1,7 & 2,2 & 2,9 & 2,3 & 1,3 \\
\hline & \%ETANOL & 8,8 & 9,2 & 9,9 & 8,8 & 9,3 & 8,9 \\
\hline & $p H$ & 4,0 & 4,1 & 4,1 & 4,3 & 4,0 & 4,0 \\
\hline & \begin{tabular}{|l|} 
EFICIÊNCIA \\
BIOQUÍMICA
\end{tabular} & 84,4 & 86,1 & 92,7 & 91,2 & 92,7 & 81,3 \\
\hline & \begin{tabular}{|l|} 
EFICIENNCIA \\
DO \\
PROCESSO
\end{tabular} & 73,5 & 78,1 & 81,8 & 76,4 & 80,7 & 75,5 \\
\hline \multirow{5}{*}{$\begin{array}{l}\text { MOSTO } \\
\text { FERMENTADO } \\
\text { POR } 72 \text { HORAS }\end{array}$} & $A R T$ & 0,4 & 0,6 & 0,2 & 0,7 & 0,3 & 1,1 \\
\hline & \%ETANOL & 9,6 & 9,9 & 10,5 & 10,2 & 9,6 & 9,4 \\
\hline & $p H$ & 4,1 & 4,2 & 4,1 & 4,3 & 4,1 & 4,0 \\
\hline & \begin{tabular}{|l|} 
EFICIÊNCIA \\
BIOQUÍMICA
\end{tabular} & 81,9 & 86,9 & 87,7 & 92,1 & 84,7 & 84,9 \\
\hline & $\begin{array}{l}\text { EFICIÊECIA } \\
\text { DO } \\
\text { PROCESSO }\end{array}$ & 80,15 & 84,0 & 86,7 & 88,5 & 83,3 & 79,8 \\
\hline
\end{tabular}

Levedura comercial testada: Saccharomyces cerevisiae, (procedência Fleishamnn \& Royal Ltda; Itaiquara S/A; Mauri, Brasil).

Os Açúcares Redutores Totais (A.R.T.) foram determinados analiticamente e expressos em 
g/100 mL, o Etanol em graus Gay-Lussac, ${ }^{\circ} \mathrm{GL}$ (\%vol./vol.) e a concentração celular em g/L (peso seco).

Esses experimentos foram desenvolvidos com o objetivo de realizar estudos comparativos com o fermento usado na fermentação alcoólica tradicional que utiliza caldo de cana-de-açúcar como meio de crescimento e de produção de álcool ao mesmo tempo.

Os experimentos desenvolvidos com este meio natural, foram conduzidos dentro das condições de cultivo do processo de fermentação tradicional. Apenas, a temperatura foi mantida em $28^{\circ} \mathrm{C}$, ou seja, na temperatura ambiente. Na Figura 3 encontra-se o desempenho das linhagens de leveduras selecionadas e cultivadas em caldo de cana.
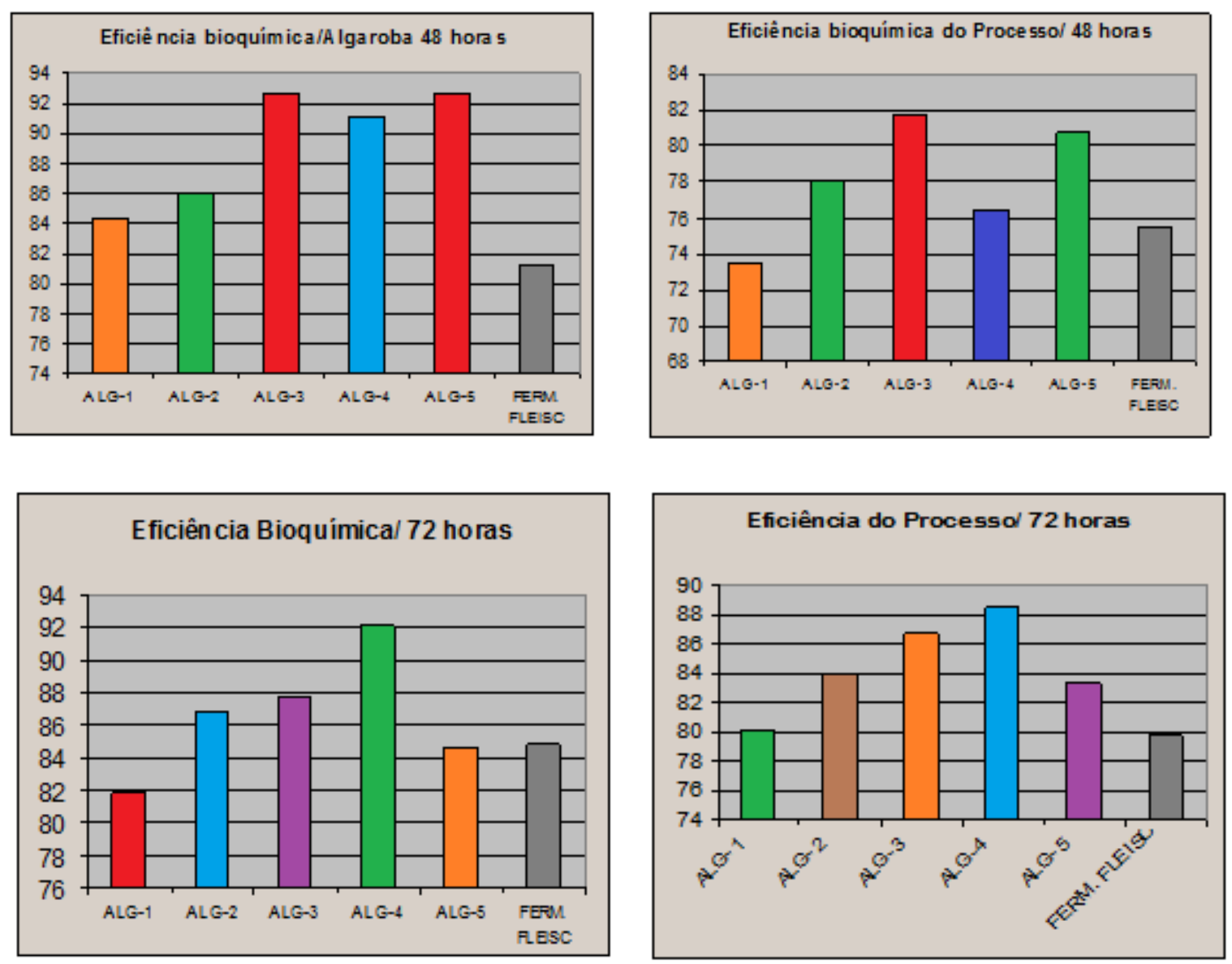

Figura 3 - Desempenho das principais linhagens de leveduras selvagens selecionadas e isoladas do caldo de algaroba.

Dentre as linhagens selecionadas, observa-se que as leveduras denominadas ALG-3 e ALG-4 foram as que mais se destacaram, inclusive superando bem, a levedura de panificação, comercialmente conhecida como Fermento Fleischmann.

As ilustrações relativas à sequiência dos gráficos acima registram as eficiências e os rendimentos das leveduras selvagens selecionadas e isoladas da vagem da algarobeira, onde se destacam as 
linhagens ALG-3 e ALG-4, o que certamente, podem ser recomendadas para uso direto nos processos de fermentação alcoólica. Embora tenham sido selecionadas cinco linhagens: ALG-1; ALG-2; ALG-3; ALG-4 e ALG-5 apenas duas se destacaram quando testadas em caldo de cana, o que ficou comprovado de acordo com o cálculo das respectivas eficiências e rendimentos do processo de fermentação. Os rendimentos de $92,7 \%$ e $91,2 \%$ mostrados assim como as eficiências de $81,8 \%$ e $76,4 \%$ justificam o seu uso em processos de fermentação. A eficiência dos processos fermentativos depende, entre outros fatores, da qualidade do microrganismo presente no processo. Enfim, pudemos inferir que o caldo de Algaroba é um meio nutriente cuja flora microbiana é capaz de proporcionar algumas linhagens interessantes para a fermentação alcoólica, as quais podem ser aplicada a determinados processos industriais.

\section{CONCLUSÕES}

As leveduras isoladas do caldo de algaroba tiveram apresentaram um bom desempenho usando o caldo de cana como meio de fermentação, inclusive, sendo mais eficaz em termos de rendimentos e eficiências, quando comparado com o fermento comercial (Fermento Feischmann).

Os testes realizados em unidades industriais de fermentação, demonstraram que as leveduras selecionadas e isoladas do caldo de algaroba são perfeitamente viáveis do ponto de vista técnico e econômico usando meio tradicional de fermentação.

\section{Referencias bibliográficas}

AGIDE, G. N. Considerações sobre a algaroba. Coletânea do Instituto de Tecnologia de Alimentos. Campinas, v.17, n.1, p.1-27 Jan./Jun., 1987.

ANDRIETTA, M. G. S.; RODRIGUES, M. I. Controle da fermentação alcoólica através de testes microbiológicos e bioquímicos. Faculdade de Engenharia de Alimentos/Unicamp 2005 Disponível em: http://www.fea.unicamp.br/extensaão. Acesso em: 2005

ARRUDA, D. T. Viabilidade técnico-economica da produção de etanol e ração a partir da algaroba no semi-árido da Paraíba. 1994. 97f. Dissertação (Mestrado em Engenharia de Produção). Centro de Tecnologia da Universidade Federal da Paraíba. João Pessoa - PB.

BARBOSA, F. A.; FARIA, G. A.; VILELA, H. Leveduras vivas na nutrição de Bovinos. Portal da Ciência e Tecnologia 2007, 168p.

ESTRELA, C.; PÉCORA, J.C. Caracterização de microrganismos. Brazilian Journal of Food Technology. v.3, n.11, p.1-6, 2003. Disponível em: http://www.livronline.com/ serviços. Acesso em: 16 de Novembro de 2006. 
FERREIRA, M.E.; GATTAPAGLIA, D. Introdução ao uso de marcadores moleculares em analise genética. 2.ed. Brasília; Embrapa/Cenargen, 1996. 220p.

LALUCE, C. Fermentação alcoólica: Ciência e Tecnologia Fermentec Editora/ Fermentec News. Rio Claro, SP. 2004, 298p.

MUNIZ, M. B. Processamento das vagens de algaroba (Prosopolis juliflora) para produção de bioprodutos. - Tese. 145 f il. 2009.

MOREIRA, S. R.; SCHWAN, R. F.; CARVALHO, E. P. Isolamento e identificação de leveduras e fungos filamentosos em iogurtes. Brazilian Journal of Microbiology, v.32, n.2, p.117-122 Abr./Jun. 2001.

OLIVEIRA, E. G. Isolamento de leveduras selvagens de vagens da algarobeira. Maceió, AL 2005, 12p. ( Informativo do Centro de Tecnologia da Universidade Federal de Alagoas - UFAL)

NETO, C. E. R. Caracterização e identificação genética de leveduras Saccharomyces cerevisiae usada na produção de álcool. Maceió, AL , 2005. 21p. (Informativo Laboratório de Biotecnologia Avançada da UFAL)

SCAVUZZI, J. A. Cariotipagem de Leveduras Oriundas da Fermentação Alcoólica. Recife, 2007, 21p. (Boletim Bioprodutividade/Incubação e Inovação Tecnológica). WILLIAMS, J. G. K.; KUBELIK, A.R.; LIVAK, K.J.; RAVASLSKI, J.A.; TINGEY, S.V. DNA polymorphisms amplified by arbitrary primers are useful as genetic markers. Nucleic Acids Research, v.12. n.18, p.351-539, 1990www.homeopatiaveterinaria..com.br 